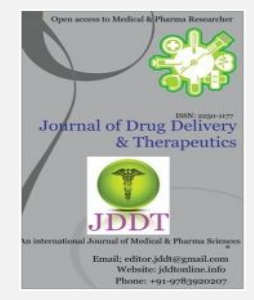

\title{
STUDY OF MAO-B INHIBITOR ANALOUGES FOR PARKINSON'S DISEASE THROUGH CADD APPROACHES
}

\author{
Manish Bachhar*, B.K. Singh \\ Department of Pharmaceutical Sciences, Bhimtal, Kumaun University, Nainital-263136, India
}

\begin{abstract}
New derivatives are designed as target directed MAO-B Inhibitors for medical care of the patients for neurodegenerative disorder. Molecular design and estimated pharmacokinetic properties have been evaluated by using Inventus $\mathrm{v} 1.1$ software. The binding mode of the proposed compounds with target protein i.e. 1S2Q was evaluated and the resulting data from docking studies explained that newly designed derivatives have high and better affinity towards target protein. Based on these properties, the binding affinities are used for speeding up drug discovery process by eliminating less potent compounds from synthesis.
\end{abstract}

Keywords: MAO-B, Inventus, Target protein, Neurodegenerative, Docking.

Article Info: Received 06 Sep, 2018; Review Completed 03 Oct 2018; Accepted 07 Oct 2018; Available online 15 Oct 2018

Cite this article as:

Bachhar M, Singh BK, Study of MAO-B inhibitor analouges for parkinson's disease through CADD approaches, Journal of Drug Delivery and Therapeutics. 2018; 8(5-s):240-250 DOI: http://dx.doi.org/10.22270/jddt.v8i5-s.1965

*Address for Correspondence:

Manish Bachhar, Department of Pharmaceutical Sciences, Bhimtal, Kumaun University, Nainital-263136, India

\section{INTRODUCTION}

Computer aided drug design (CADD) is the process which facilitates computational approaches and resources that are used in Design and Discovery of new therapeutic agents. ${ }^{1}$ The discovery and development of new drugs are long, tedious, complex and costly process. $^{2}$ It is a typical drug discovery cycle, which takes 10-15 years and million dollar currency to introduce in marketplace. That's why CADD has been widely used in Pharmaceutical field to accelerate the designing process in most efficient way. ${ }^{3}$

\section{MAO-B Inhibitor as therapeutic target}

Parkinson's disease is a neurodegenerative disorder of the brain resulting in Dopamine deficiency caused by the progressive death of dopaminergic neurons. Selegiline is first class drug which inhibits Dopamine metabolism but its therapeutic effects are compromised by its neurotoxic metabolites. To overcome this obstacle, a novel MAO-B inhibitor Rasagiline was developed. It is biotransfered to aminoindan, a non-amphetamine compound. It is effective as monotherapy or adjunct to L-dopa for patients with Parkinson's patients. ${ }^{4}$

\section{MATERIAL AND METHODS}

Computing is used in various ways in drug discovery. Important example includes QSAR and Structure Based methods. Here we focused on Structure based methods.

These methods show increasing utility for the discovery of the lead compounds and for refinement of lead compounds and for re-engineering of drug to overcome certain types of resistance. It becomes important in the rapid growth in structural data and determined as part of a focused drug-discovery effort with a wellcharacterized target. ${ }^{5}$

Here, Structure based Drug design approaches were employed to develop potent MAO-B inhibitors for the Parkinson drug candidate.

\section{Overview of the Process}

Methods used to design inhibitors ranged from graphical visualization of the ligand in the binding site cavity to calculation of relative binding affinities using molecular mechanics. It is important to understand the interaction of the ligand with its receptor protein by examining the 3 -D structure of the protein target in complex with the ligand. It helps in studying the interaction with the 
protein, while modifying the analogues with the receptor or enzyme for better results. With the knowledge of the structure of target-protein-ligand complex, the structure activity relationship of compounds, suggest new analogues to synthesize and develop new ligand moieties. This methodology is known as Structure based Drug Design. ${ }^{6}$

\section{Steps involved in structure based drug design}

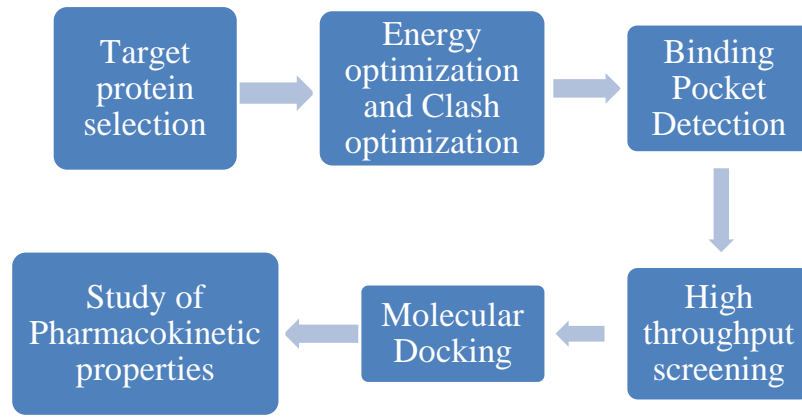

\section{Target Protein Selection}

The processes of structure based drug design often proceed through multiple cycles. The first cycle includes cloning, purification and structure determination of the target protein by one of three principle methods:-
(1) X-ray crystallography
(2) NMR
(3) Homology Modeling

The ideal target macromolecule for Structure based drug design is one that is closely linked to human disease and binds a small molecule in order to carry out a function. RCSB-PDB (Research Collaboratory for Structural
Bioinformatics-Protein Data Bank) is the most common source of crystal structure and structural information for drug design. The crystal structure of MAO-B in complex with Rasagiline was selected for this study and obtained from RCSB-PDB with PDB ID- 1S2Q. It has total 2 Chains, Resolution- 2.07£. The structure is shown in figure. Using the structural information obtained through PDB, the 3-D structure of target was then prepared for drug design program.

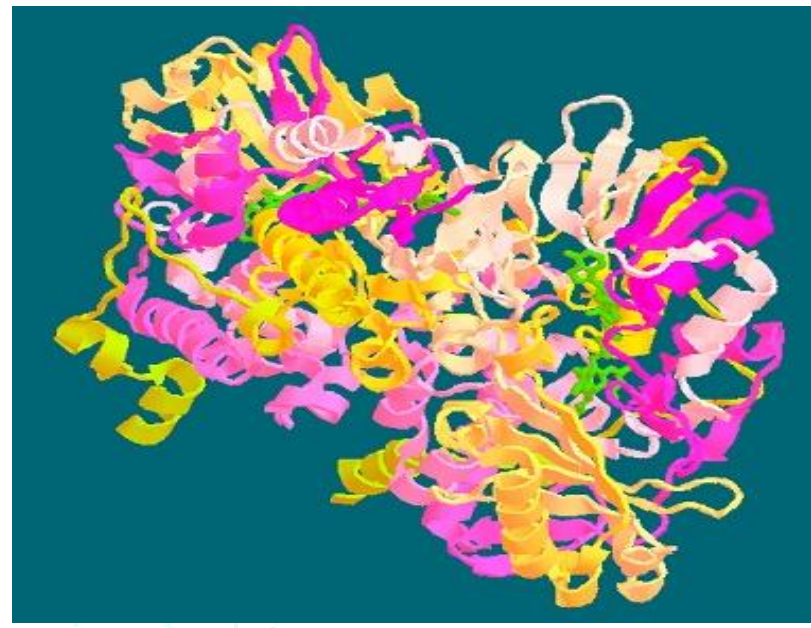

Figure 1: Crystal structure of MAO-B in complex with N-propargyl-1(R)-aminoindan (Rasagiline)

\section{Energy Minimization}

In silico processing of protein structure starts with energy minimization, this tool uses steepest descent (SD) and Conjugate gradient (CG) algorithm to minimize the potential energy of protein molecule.
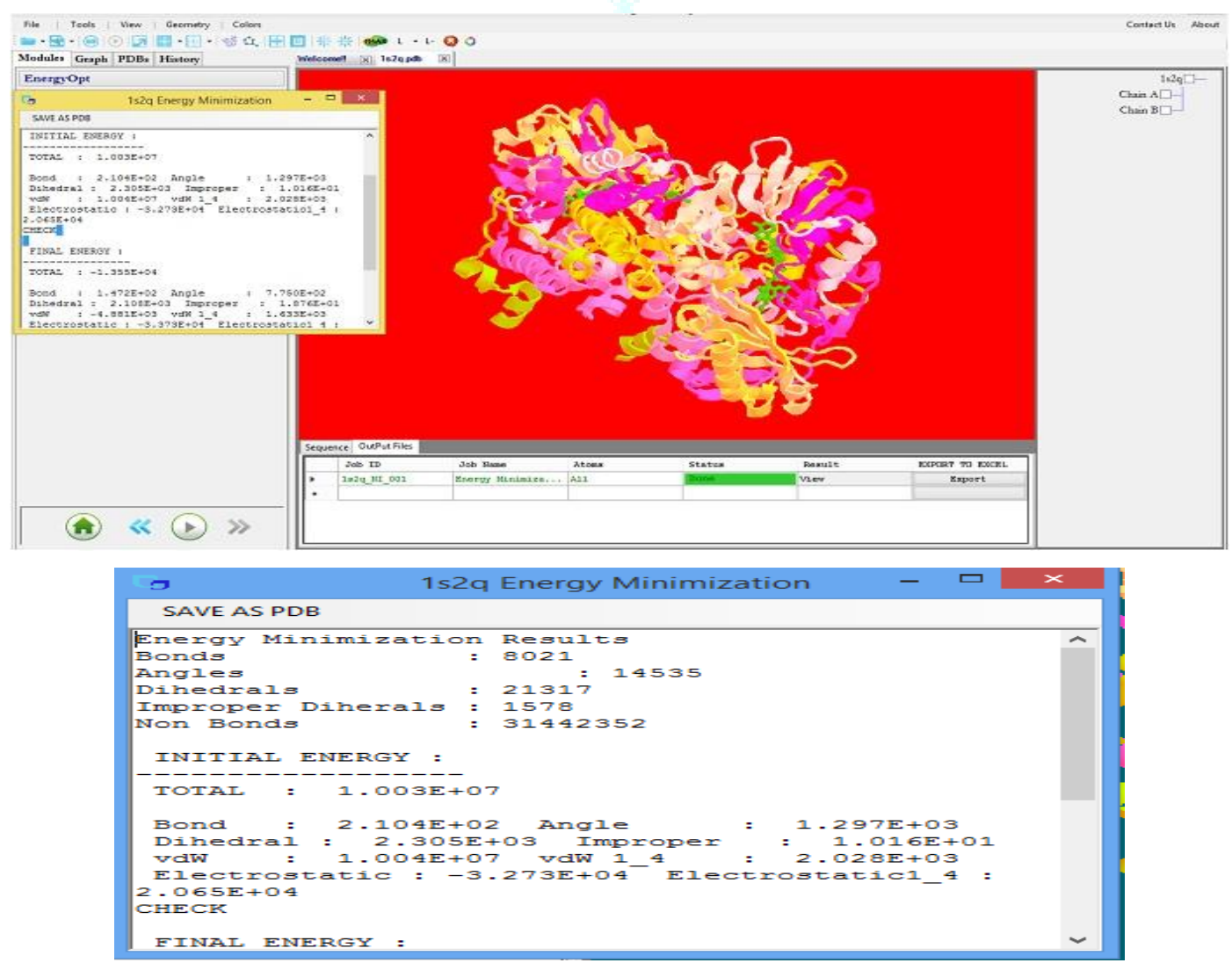

Figure 2: Snapshot of Energy Minimization 


\section{Clash Optimization}

Many times energy minimizes is unable to remove all clashes from protein structure which may create difficulty in outcome during Docking of Protein and Ligand inhibitor. It is based on Monte Carlo technique is used to remove clashes from protein structure. It can fix the number of cycles; we usually run 25-30 cycles and observe the effects of optimization process.
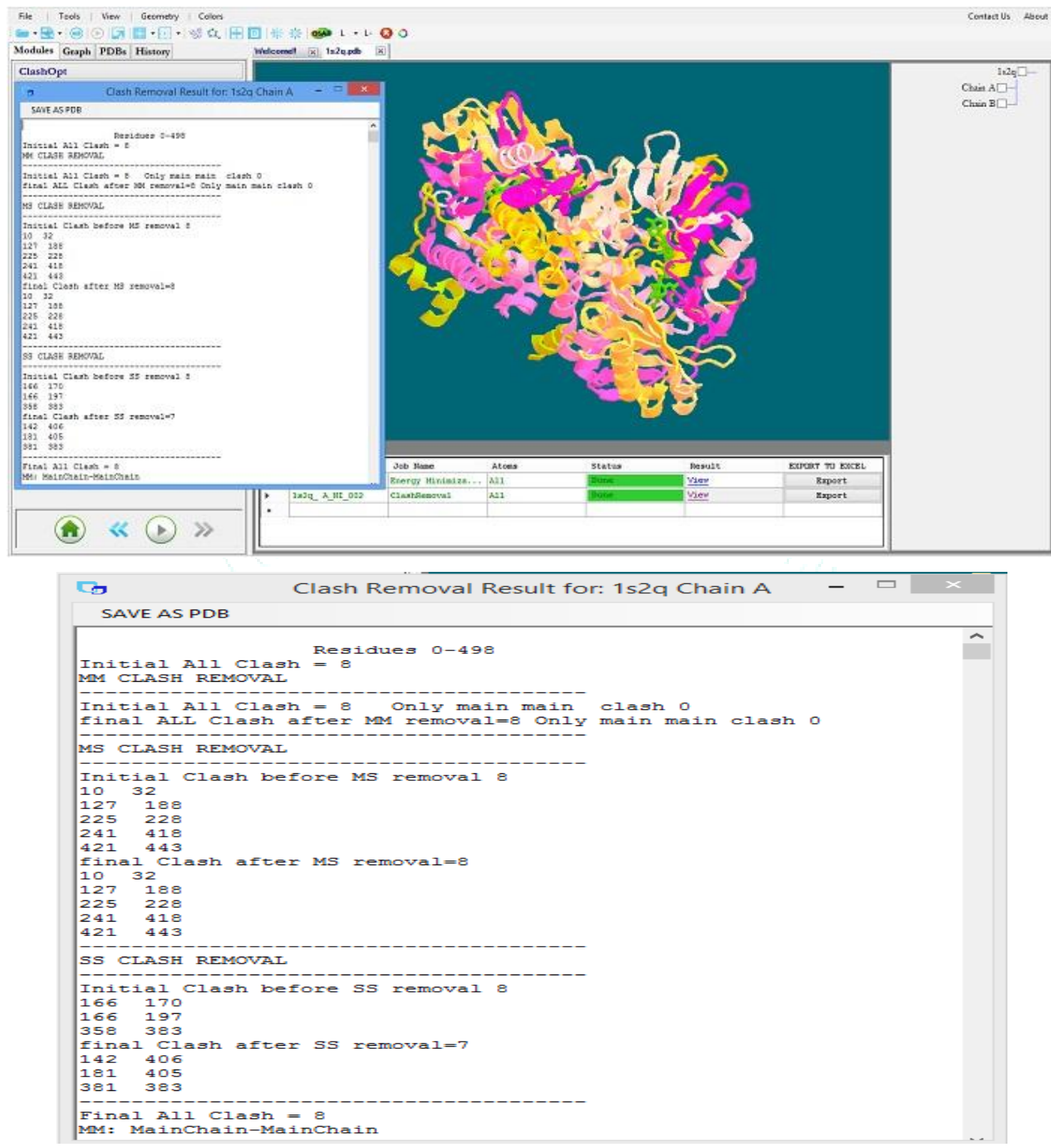

Figure 3: Snapshot of Clash Optmization

\section{Binding Pocket Detection}

In Inventus v1.1 software, the active site detection in a protein structure is based on its geometry like volume, depth. We identified maximum 10 active sites with ranking order and selected the best active site. We also compared the active site residues of Reference Ligand and found that each of the residues of active site lies in Cavity 2. So Cavity 2 is considered as active site or binding pocket. The active site residue within the distance of $5 \AA$ were- GLY 58, TYR 60, PHE 168, LEU 171, CYS 172, ILE 198, ILE 198, GLN 206, TYR 326, LEU 328, PHE 343, TYR 398, TYR 435.

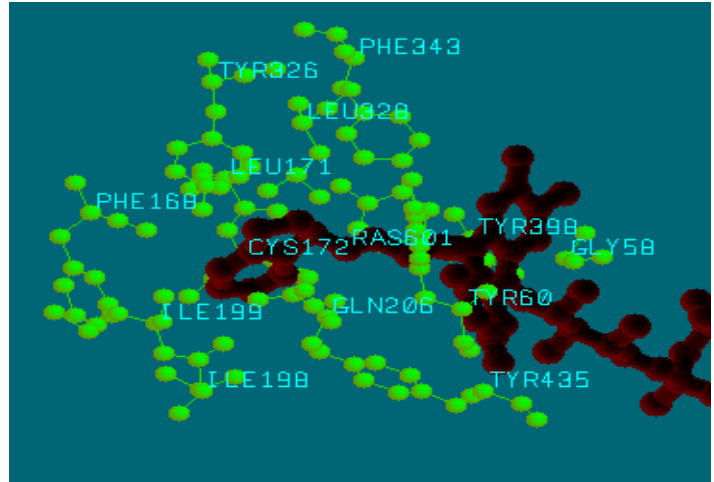

Figure 4: Active site residues of $1 S 2 Q$ with Rasagiline. 


\section{High Throughput Screening}

Virtual screening process needs the speed and accuracy, where speed is the time required in screening and accuracy is finding true positives from the screened compound pool of library.
It is based on the protocol developed to remove the false positive from the screened molecules. Molecule can be screened using customized library as well as embedded library.

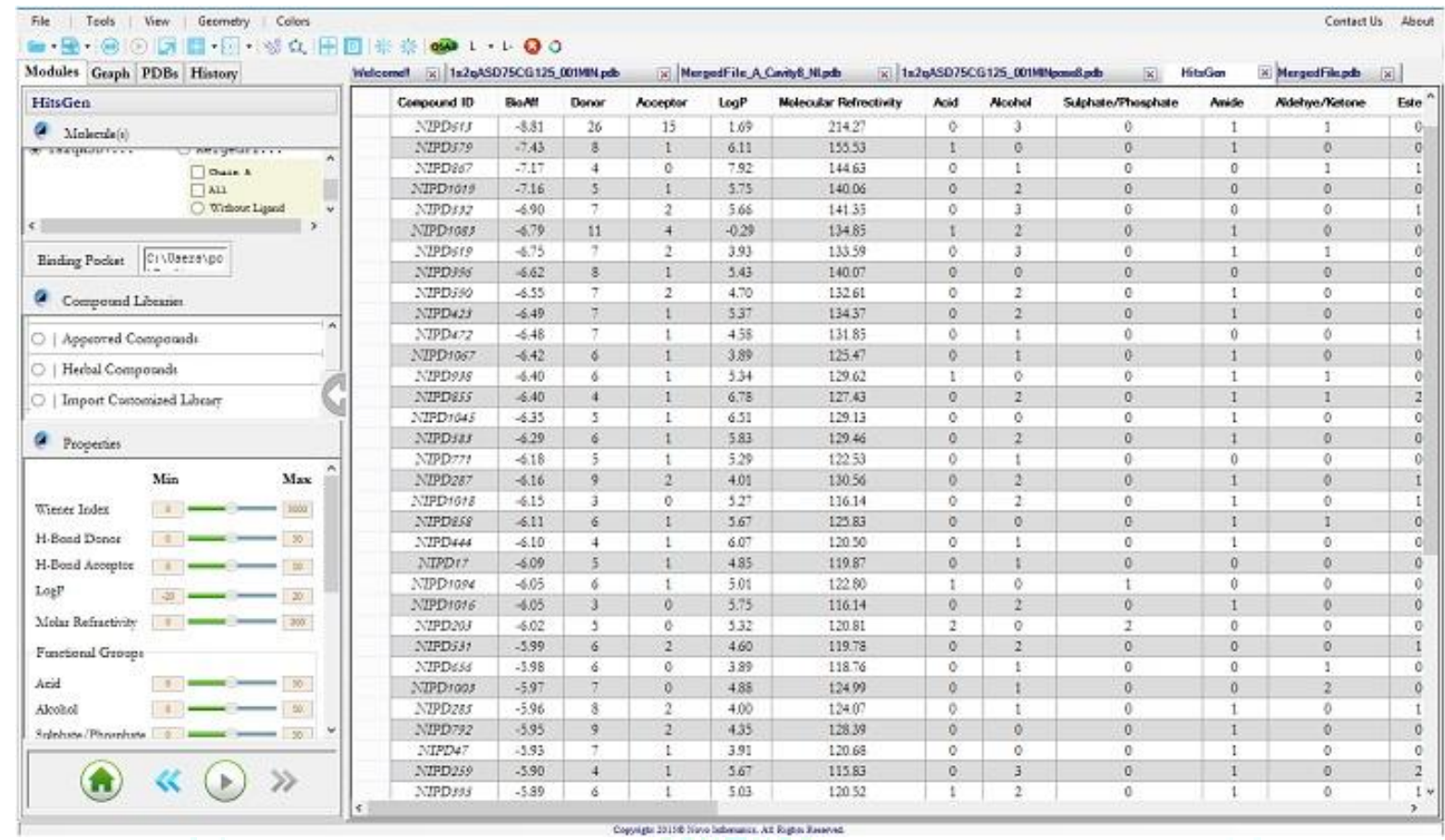

Figure 5: List of Screened compounds by Hits-Gen

\section{Molecular Docking}

It starts with the knowledge of active sites or with the information about the ligand receptor complex. It predicts the non-covalent binding of macromolecule (receptor) and a small molecule (ligand). The key characteristic of good docking program is its ability to reproduce experimental binding poses of ligand.

Docking of small molecules to receptor structures has become increasingly important in the context of drug discovery. ${ }^{7-9}$ Over the past few years a number of methods have been developed for performing (relatively) fast predictions for a series of molecules regarding their ability to bind to a protein binding site. ${ }^{10}$

Analogue design is usually defined as the modification of a drug molecule in order to prepare a new molecule showing chemical and biological similarity with the original model compound. In this study Rasagiline was selected as reference molecule and its structure was obtained from PubChem. In the first step, the reference molecule was docked into the active site and its binding affinity was noted i.e. $(-13.54 \mathrm{kcal} / \mathrm{mol})$. The reference molecule was modified to develop more potent molecules/compounds based on the data of high throughput screening and SAR information.

\section{Pose prediction versus affinity prediction}

Technically, the placement of the molecules in the region of interest (e.g. the receptor-binding site) is referred to as 'docking', whereas the prediction of affinity is referred to as 'scoring'. The distinction between docking and scoring defines also the two major technical challenges faced by docking programs: to predict the binding mode of a molecule correctly (herewith also referred to as 'pose prediction', where 'pose' refers to the orientation and conformation of a molecule at the receptor binding site $)^{11}$ and to predict the binding affinity of compounds (or to produce a relative rank-ordering for a number of compounds) in a reliable manner. ${ }^{12}$

In this study, prepared protein and all analogues were subjected to docking using Novo-Docker module of Inventus v1.1 software to carry out the protein analogue interaction studies.

\section{RESULT AND DISCUSSION}

By using Structure based drug design, we have designed 15 analogues. Docking was performed for analysis of protein ligand interactions using Inventus v1.1 software and results are shown in table 1. 
Table 1: Docking results of designed analogues

\begin{tabular}{|c|c|c|}
\hline S.No. & Compounds & Properties \\
\hline 1 & $\begin{array}{c}\text { 6,7-dihydro-5H-cyclopenta[b]pyridin-7-yl ethylcarbamate } \\
\text { Chemical Formula: } \mathrm{C}_{11} \mathrm{H}_{14} \mathrm{~N}_{2} \mathrm{O}_{2}\end{array}$ & $\begin{array}{l}\text { BioAff: }-14.12 \\
\text { M.W.: } 206.25 \\
\text { HBA : } 4 \\
\text { HBD : } 2 \\
\text { Log P : } 2.05\end{array}$ \\
\hline 2 & $\begin{array}{l}\text { (R)-7-(ethynyloxy)-6,7-dihydro-5H-cyclopenta[b]pyridine } \\
\text { Chemical Formula: } \mathrm{C}_{10} \mathrm{H}_{9} \mathrm{NO}\end{array}$ & $\begin{array}{l}\text { BioAff: }-14.10 \\
\text { M.W. : } 159.19 \\
\text { HBA : } 2 \\
\text { HBD : } 1 \\
\text { Log P : } 1.63\end{array}$ \\
\hline 3 & $\begin{array}{l}(R) \text {-(R)-6,7-dihydro-5H-cyclopenta[b]pyridin-7-yl 2-methoxy-2-phenylacetate } \\
\text { Chemical Formula: } \mathrm{C}_{17} \mathrm{H}_{17} \mathrm{NO}_{3}\end{array}$ & $\begin{array}{l}\text { BioAff: }-14.12 \\
\text { M.W. : } 283.33 \\
\text { HBA : } 4 \\
\text { HBD : } 1 \\
\text { Log P : } 2.55\end{array}$ \\
\hline 4 & $\begin{array}{c}\text { (R)- } N \text {-benzyl-6-bromo-2,3-dihydro- } 1 H \text {-inden-1-amine } \\
\text { Chemical Formula: } \mathrm{C}_{16} \mathrm{H}_{16} \mathrm{BrN}\end{array}$ & $\begin{array}{l}\text { BioAff: }-14.01 \\
\text { M.W. : } 302.22 \\
\text { HBA : } 1 \\
\text { HBD : } 1 \\
\text { Log P : } 3.12\end{array}$ \\
\hline 5 & 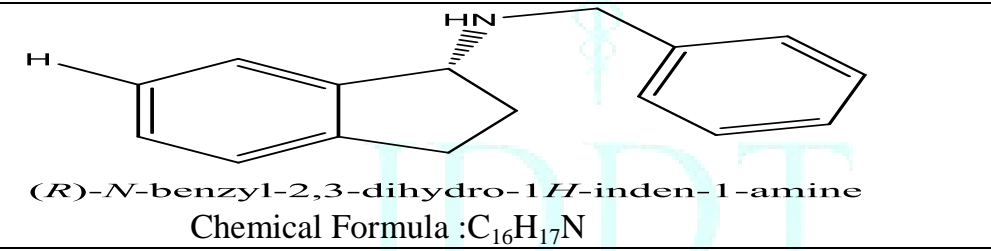 & $\begin{array}{l}\text { BioAff: }-14.12 \\
\text { M.W. : } 223.32 \\
\text { HBA : } 1 \\
\text { HBD : } 1 \\
\text { Log P : } 3.58\end{array}$ \\
\hline 6 & $\begin{array}{c}\text { (R)- } N \text {-benzyl-6-methyl-2,3-dihydro- } 1 H \text {-inden-1-amine } \\
\text { Chemical Formula: } \mathrm{C}_{17} \mathrm{H}_{19} \mathrm{~N}\end{array}$ & $\begin{array}{l}\text { BioAff: }-14.01 \\
\text { M.W. : } 237.35 \\
\text { HBA : } 1 \\
\text { HBD : } 1 \\
\text { Log } P: 3.70\end{array}$ \\
\hline 7 & 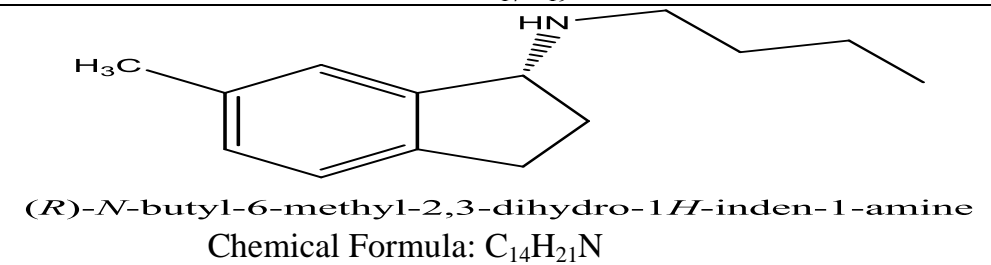 & $\begin{array}{l}\text { BioAff : }-14.12 \\
\text { M.W. : } 203.33 \\
\text { HBA : } 1 \\
\text { HBD : } 1 \\
\text { Log P: } 3.61\end{array}$ \\
\hline 8 & $\begin{array}{l}\text { (R)-6-bromo- } N \text {-butyl-2,3-dihydro- } 1 H \text {-inden-1-amine } \\
\text { Chemical Formula: } \mathrm{C}_{13} \mathrm{H}_{18} \mathrm{BrN}\end{array}$ & $\begin{array}{l}\text { BioAff : }-14.12 \\
\text { M.W. : } 268.20 \\
\text { HBA : } 2 \\
\text { HBD : } 2 \\
\text { Log } P: 1.53\end{array}$ \\
\hline
\end{tabular}




\begin{tabular}{|c|c|c|}
\hline 9 & $\begin{array}{ll}(R)-N \text {-butyl-5-fluoro-2,3-dihydro-1 } H \text {-inden-1-amine } \\
\text { Chemical Formula: } \mathrm{C}_{13} \mathrm{H}_{18} \mathrm{FN}\end{array}$ & $\begin{array}{l}\text { BioAff: }-14.12 \\
\text { M.W. : } 207.29 \\
\text { HBA : } 4 \\
\text { HBD : } 2 \\
\text { Log P : } 2.05\end{array}$ \\
\hline 10 & (R)-N-(prop-2-yn-1-y1)-6,7-dihydro-5H-cyclopenta[b]pyridin-5-amine & $\begin{array}{l}\text { BioAff: }-14.09 \\
\text { M.W : } 172.23 \\
\text { HBA : } 1 \\
\text { HBD : } 1 \\
\text { Log P : } 2.70\end{array}$ \\
\hline 11 & $\begin{array}{l}\text { 6,7-dihydro-5H-cyclopenta[b]pyridin-5-yl ethylcarbamate } \\
\text { Chemical Formula: } \mathrm{C}_{11} \mathrm{H}_{14} \mathrm{~N}_{2} \mathrm{O}_{2}\end{array}$ & $\begin{array}{l}\text { BioAff: }-14.12 \\
\text { M.W.: } 187.28 \\
\text { HBA : } 1 \\
\text { HBD : } 1 \\
\text { Log P : } 3.01\end{array}$ \\
\hline 12 & $\begin{array}{l}\text { (R)-3-(al1y1(ethy1)amino)-2,3-dihydro-1 } \mathrm{H} \text {-inden-5-ol } \\
\text { Chemical Formula: } \mathrm{C}_{14} \mathrm{H}_{19} \mathrm{NO}\end{array}$ & $\begin{array}{l}\text { BioAff: }-14.01 \\
\text { M.W : } 191.24 \\
\text { HBA : } 1 \\
\text { HBD : } 1 \\
\text { Log P : } 2.92\end{array}$ \\
\hline 13 & $\begin{array}{l}\text { (R)-N,N-di(prop-2-yn-1-y1)-2,3-dihydro-1 H-inden-1-amine } \\
\text { Chemical Formula: } \mathrm{C}_{15} \mathrm{H}_{15} \mathrm{~N}\end{array}$ & $\begin{array}{l}\text { BioAff: }-14.01 \\
\text { M.W : } 272.34 \\
\text { HBA : } 4 \\
\text { HBD : } 1 \\
\text { Log P : } 2.84\end{array}$ \\
\hline 14 & $\begin{array}{c}\text { (R)-N-(2-chloroally1)-2,3-dihydro-1 } \mathrm{H} \text {-inden-1-amine } \\
\text { Chemical Formula: } \mathrm{C}_{12} \mathrm{H}_{14} \mathrm{ClN}\end{array}$ & $\begin{array}{l}\text { BioAff: }-14.01 \\
\text { M.W : } 277.36 \\
\text { HBA : } 2 \\
\text { HBD : } 1 \\
\text { Log P : } 3.46\end{array}$ \\
\hline 15 & $\begin{array}{l}\text { (R)-N-(2-fluoroally1)-2,3-dihydro-1 } \mathrm{H} \text {-inden-1-amine } \\
\text { Chemical Formula: } \mathrm{C}_{12} \mathrm{H}_{14} \mathrm{FN}\end{array}$ & $\begin{array}{l}\text { BioAff: }-14.12 \\
\text { M.W : } 291.39 \\
\text { HBA : } 2 \\
\text { HBD : } 1 \\
\text { Log P : } 3.92\end{array}$ \\
\hline
\end{tabular}


After molecular docking, we have analyzed the ADME (structure only) properties of the all designed analogues by using pharmopredicta module of inventus. The key features of this module, which were used in our study, are described below:

\section{ADME (Structure Based)}

1) Human Absorption, FDp (\%) binned

Results are classified as

- Low (0-33\% absorbed)

- Medium (33-64\% absorbed)

- High (67-100\% absorbed)
2) Caco-2 Permeability ( $\rightarrow$ B or apical to basolateral) Peff at pH $7.4(\mathrm{~cm} / \mathrm{s})$

Additional output data provided by pkEXPRESS plus module only:

3) Caco-2 Permeability ( $\rightarrow$ A or basolateral to apical)

Peff at $\mathrm{pH} 7.4(\mathrm{~cm} / \mathrm{s})$

4) Efflux at $\mathrm{pH} 7.4(0$ if $\leq 5.3,1$ if $>5.3)$

5) Blood brain barrier permeability ( 0 if no penetration, 1 if penetration)

6) Protein binding ( 0 if $\leq 85 \%$ or 1 if $>85 \%$ )

7) Volume of Distribution at steady state (VDSS; liters)

Table 2: Caco-permeability and efflux parameters of designed compounds

\begin{tabular}{|l|l|l|l|l|l|l|}
\hline Compound & Caco74ab & $\begin{array}{l}\text { Caco 74ab } \\
\text { Confidence }\end{array}$ & Caco74 ba & $\begin{array}{l}\text { Caco 74ba } \\
\text { confidence }\end{array}$ & efflux & $\begin{array}{l}\text { Efflux } \\
\text { Confidence }\end{array}$ \\
\hline Reference & $4.90 \mathrm{E}-05$ & High & $5.73 \mathrm{E}-05$ & High & 0 & High \\
\hline Analog 1 & $4.90 \mathrm{E}-05$ & Low & $5.67 \mathrm{E}-05$ & High & 0 & High \\
\hline Analog 2 & $4.90 \mathrm{E}-05$ & High & $5.73 \mathrm{E}-05$ & High & 0 & High \\
\hline Analog 3 & $4.90 \mathrm{E}-05$ & Medium & $5.43 \mathrm{E}-05$ & High & 0 & High \\
\hline Analog 4 & $4.90 \mathrm{E}-05$ & Medium & $5.73 \mathrm{E}-05$ & High & 0 & High \\
\hline Analog 5 & $4.90 \mathrm{E}-05$ & Medium & $5.63 \mathrm{E}-05$ & High & 0 & High \\
\hline Analog 6 & $4.90 \mathrm{E}-05$ & Low & $5.06 \mathrm{E}-05$ & High & 0 & High \\
\hline Analog 7 & $4.90 \mathrm{E}-05$ & Low & $4.79 \mathrm{E}-05$ & High & 0 & High \\
\hline Analog 8 & $4.90 \mathrm{E}-05$ & Low & $4.80 \mathrm{E}-05$ & High & 0 & High \\
\hline Analog 9 & $4.90 \mathrm{E}-05$ & Medium & $4.54 \mathrm{E}-05$ & High & 0 & High \\
\hline Analog 10 & $4.90 \mathrm{E}-05$ & Medium & $5.73 \mathrm{E}-05$ & High & 0 & High \\
\hline Analog 11 & $4.90 \mathrm{E}-05$ & Medium & $2.66 \mathrm{E}-05$ & High & 0 & High \\
\hline Analog 12 & $4.90 \mathrm{E}-05$ & Medium & $5.43 \mathrm{E}-05$ & High & 0 & High \\
\hline Analog 13 & $4.90 \mathrm{E}-05$ & Low & $5.06 \mathrm{E}-05$ & High & 0 & High \\
\hline Analog 14 & $4.90 \mathrm{E}-05$ & Medium & $4.54 \mathrm{E}-05$ & High & 0 & High \\
\hline Analog 15 & $4.90 \mathrm{E}-05$ & Medium & $4.54 \mathrm{E}-05$ & High & 0 & High \\
\hline
\end{tabular}

Table 3: bbb, fdp, vdss parameters of designed compounds

\begin{tabular}{|l|l|l|l|l|l|l|l|l|}
\hline $\begin{array}{l}\text { Compound } \\
\text { ID }\end{array}$ & BBB & $\begin{array}{l}\text { BBB } \\
\text { Conf. }\end{array}$ & Fdp & Fdp conf. & Probind & $\begin{array}{l}\text { Probind } \\
\text { Conf. }\end{array}$ & $\begin{array}{l}\text { Vdss } \\
\text { Conf. }\end{array}$ \\
\hline Reference & 1 & High & High & High & 1 & High & 1000 & High \\
\hline Analog 1 & 1 & Low & High & Low & 0 & Medium & 1000 & High \\
\hline Analog 2 & 1 & High & High & Medium & 0 & Medium & 100 & High \\
\hline Analog 3 & 1 & Low & High & Low & 0 & Medium & 1000 & High \\
\hline Analog 4 & 1 & High & High & Medium & 1 & Medium & 10 & High \\
\hline Analog 5 & 1 & Low & High & Low & 1 & High & 1000 & High \\
\hline Analog 6 & 1 & Low & High & Low & 1 & High & 1000 & High \\
\hline Analog 7 & 1 & Low & High & Low & 1 & Medium & 1000 & High \\
\hline Analog 8 & 1 & Low & High & Low & 0 & Low & 1000 & High \\
\hline Analog 9 & 1 & High & High & Medium & 1 & Medium & 10 & High \\
\hline Analog 10 & 1 & High & High & Medium & 1 & Medium & 10 & High \\
\hline Analog 11 & 1 & High & High & Medium & 1 & Medium & 100 & High \\
\hline Analog 12 & 1 & High & High & Medium & 1 & Medium & 1000 & High \\
\hline Analog 13 & 1 & High & High & Medium & 1 & Medium & 10 & High \\
\hline Analog 14 & 1 & High & High & Medium & 1 & Medium & 1000 & High \\
\hline Analog 15 & 1 & High & High & Medium & 1 & Medium & 10 & High \\
\hline
\end{tabular}


A large percentage of the proposed analogs were eliminated by considering Lipinski rule of five and by evaluating their physicochemical properties, binding affinities based on docking and ADME properties. The analogues having similar pharmacokinetic properties as reference and with higher docking scores i.e. compound $1,2,3,4,5,6,7,8,9,10,11,12,13,14,15$ have been considered as the potent analogues, where the reference drug rasagiline has shown the docking score 13.54 and docking scores of other ligands was shown in the Table 1.

Binding interactions of the designed leads are described as follows:

\section{Compound 1: 6, 7-dihydro-5H-cyclopenta[b]pyridin-} 7-yl ethylcarbamate

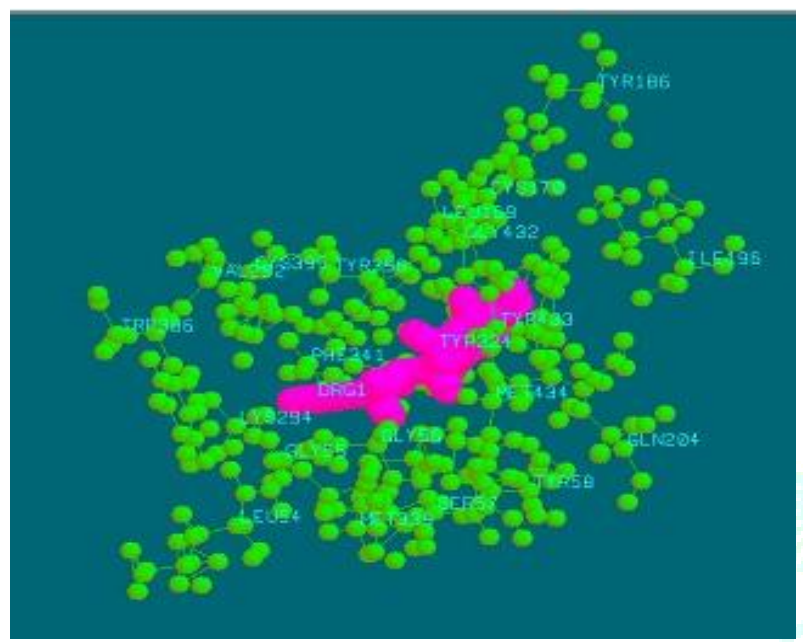

Figure 6: Binding mode of compound 1 with 1S2Q

The proposed binding mode of compound 1 revealed an affinity value of $-14.12 \mathrm{kcal} / \mathrm{mol}$. Residues SER 57, TYR 58, CYS 170, TYR 186, ILE 196, GLN 204, VAL 292, CYS 395, GLY 432, TYR 433, MET 434 shows electrostatic interaction with compound 1 and hydrophobic cleft was formed by LEU 54, GLY 55, GLY 56, LEU 169, LYS 294, TYR 324, MET 339, PHE 341, TYR 396.

Compound 4: (R)-N-benzyl-6-bromo-2, 3-dihydro-1$H$-inden-1- amine

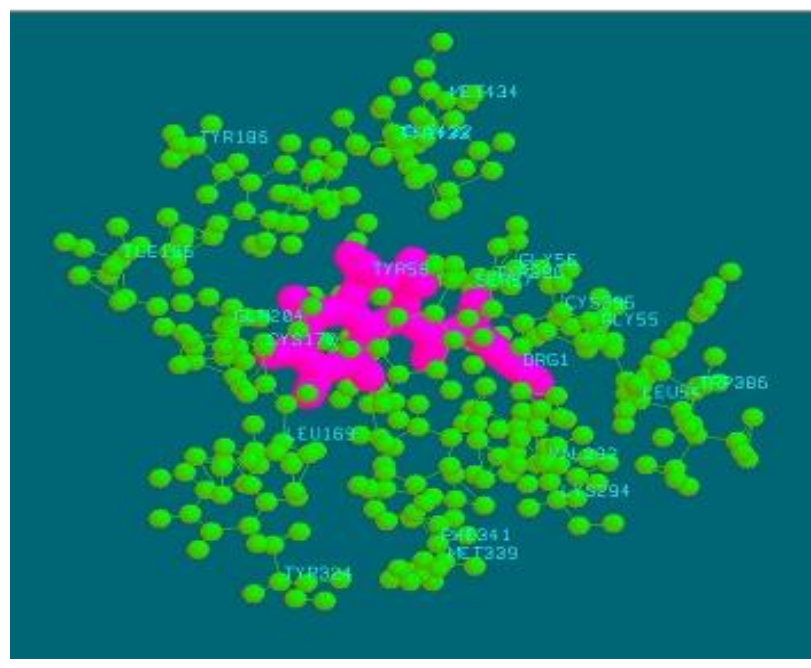

Figure 7: Binding mode of compound 4 with $1 \mathrm{~S} 2 \mathrm{Q}$
The proposed binding mode of compound 4 revealed an affinity value of $-14.01 \mathrm{kcal} / \mathrm{mol}$. Residues SER 57, TYR 58, CYS 170, TYR 186, ILE 196, GLN 204, GLY 432, TYR 433, MET 434 shows electrostatic interaction with compound 4 and hydrophobic cleft was formed by LEU 54, GLY 56, LEU 169, TYR 324, MET 339, PHE 341, TYR 396.

\section{Compound 5: (R)-N-Benzyl-2,3-dihydro-1H-1inden- 1-amine}

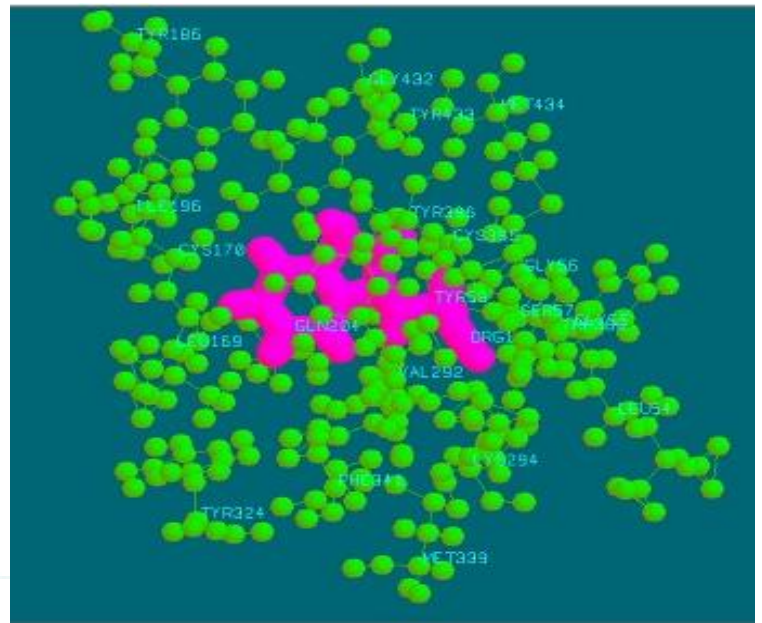

Figure 8: Binding mode of compound 5 with 1S2Q

The proposed binding mode of compound 5 revealed an affinity value of $-14.12 \mathrm{kcal} / \mathrm{mol}$. Residues SER 57, TYR 58, CYS 170, TYR 186, ILE 196, GLN 204, VAL 292, CYS 395, GLY 432, TYR 433, MET 434 shows electrostatic interaction with compound 5 and hydrophobic cleft was formed by GLY 56, LEU 169, LYS 294, TYR 324, MET 339, PHE 341 and TYR 396.

\section{Compound 6: (R)-N-benzyl-6-methyl-2,3-dihydro-} $1 H$-inden-1-amine

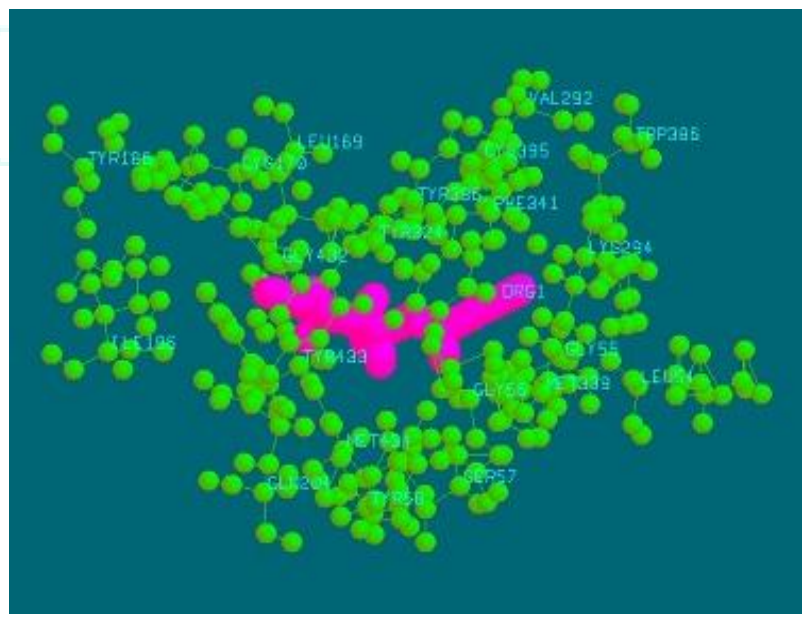

Figure 9: Binding mode of compound 6 with 1S2Q

The proposed binding mode of compound 6 revealed an affinity value of $-14.01 \mathrm{kcal} / \mathrm{mol}$. Residues SER 57, TYR 58, CYS 170, TYR 186, ILE 196, CYS 395, GLY 432, TYR 433, MET 434 shows electrostatic interaction with compound 6 and hydrophobic cleft was formed by GLY 55, GLY 56, LEU 169, LYS 294, TYR 324, MET 339 and PHE 341. 
Compound 7: (R)-N-butyl-6-methyl-2,3-dihydro-1Hinden-1-amine

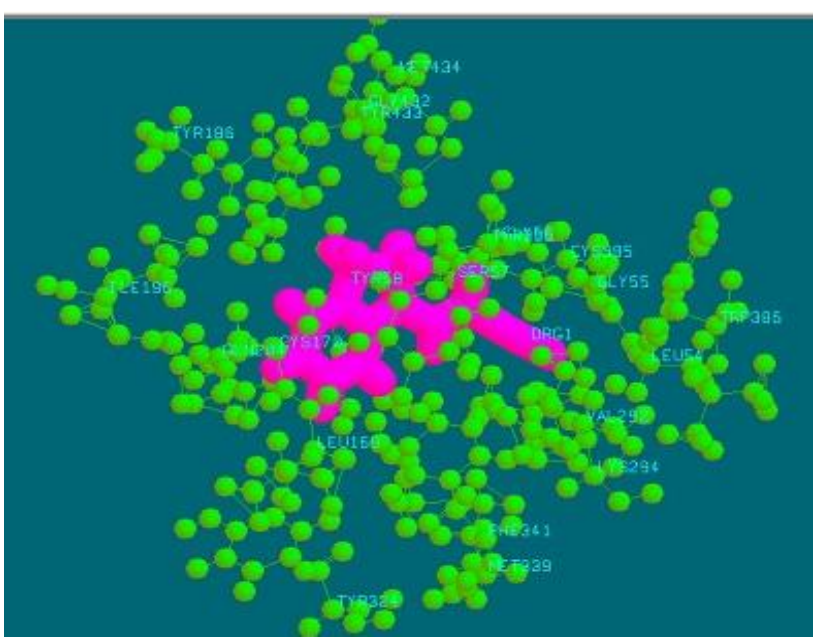

Figure 10: Binding mode of compound 7 with 1S2Q

The proposed binding mode of compound 7 revealed an affinity value of $-14.12 \mathrm{kcal} / \mathrm{mol}$. Residues SER 57 , TYR 58, CYS 170, TYR 186, ILE 196, GLN 204, CYS 395, GLY 432, TYR 433, MET 434 shows electrostatic interaction with compound 7 and hydrophobic cleft was formed by LEU 54, GLY 55, GLY 56, LEU 169, LYS 294, PHE 341 and TYR 396.

\section{Compound 8: (R)-6-bromo-N-butyl-2,3-dihyro-1H-} inden-1-amine

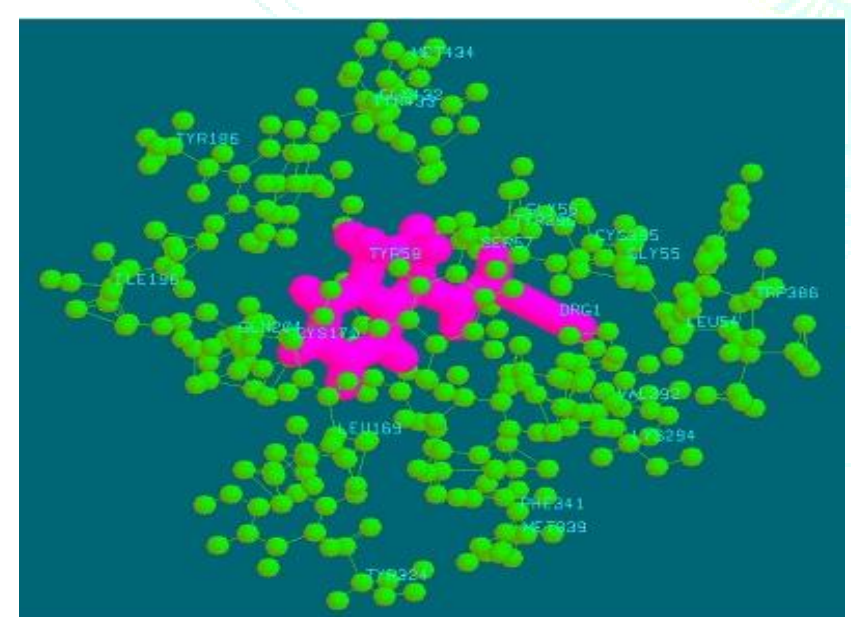

Figure 11: Binding mode of compound 8 with 1S2Q

The proposed binding mode of compound 8 revealed an affinity value of $-14.12 \mathrm{kcal} / \mathrm{mol}$. Residues SER 57, TYR 58, CYS 170, TYR 186, ILE 196, GLN 204, VAL 292, CYS 395, GLY 432, TYR 433, MET 434 shows electrostatic interaction with compound 8 and hydrophobic cleft was formed by LEU 54, GLY 55, GLY 56, LEU 169, LYS 294, TYR 324, MET 339, PHE 341, TYR 396.

\section{Compound 9: (R)-N-butyl-5-fluoro-2,3-dihyro-1H- inden-1-amine}

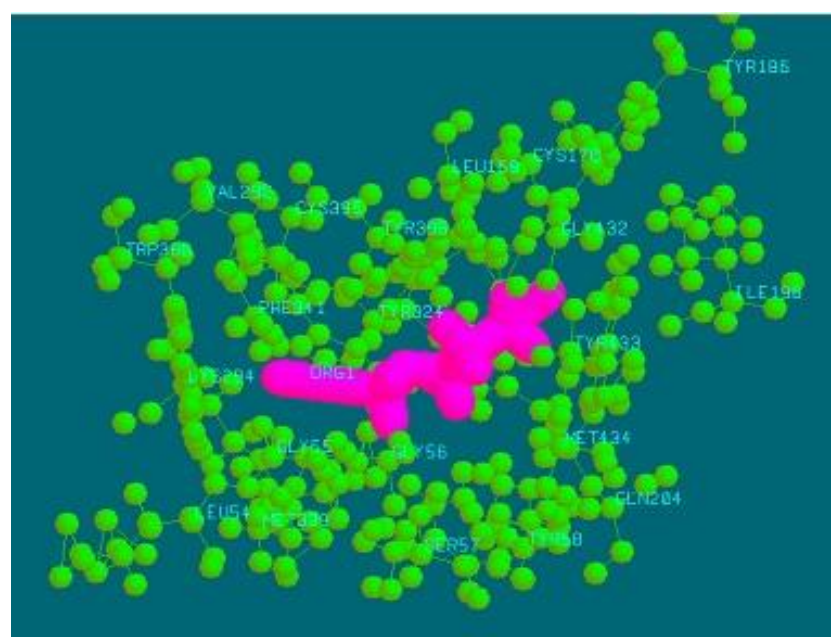

Figure 12: Binding mode of compound 9 with 1S2Q

The proposed binding mode of compound 9 revealed an affinity value of $-14.12 \mathrm{kcal} / \mathrm{mol}$. Residues SER 57 , TYR 58, CYS 170, TYR 186, ILE 196, GLN 204, VAL 292, CYS 395, GLY 432, TYR 433, MET 434 shows electrostatic interaction with compound 9 and hydrophobic cleft was formed by LEU 54, LEU 169, LYS 294, TYR 324, PHE 341 and TYR 396.

Compound 10: (R)-N-(prop-2YN-1-YL)-6,7-dihydro6,7-dihydro-5H-cyclopenta[b]pyridin-5-amine

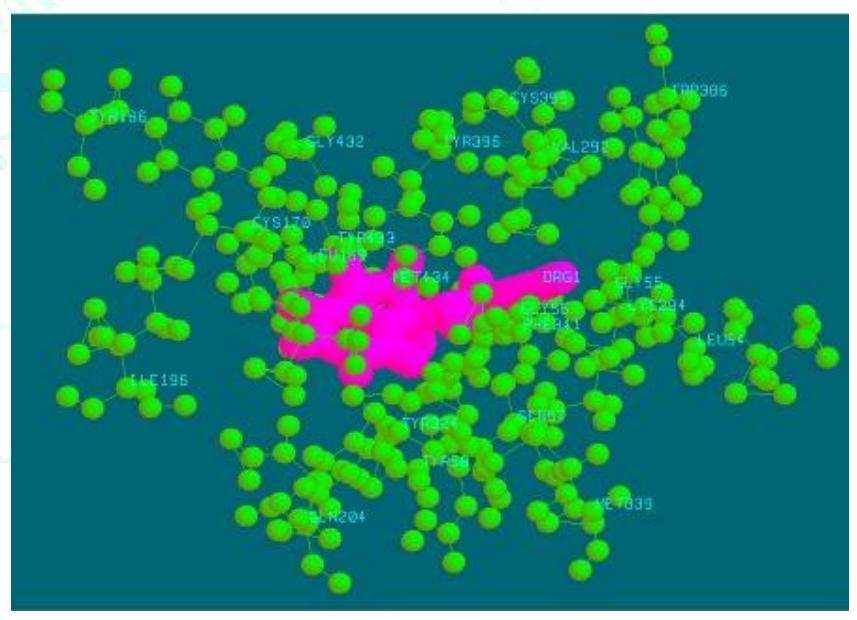

Figure 13: Binding mode of compound 10 with $1 \mathrm{~S} 2 \mathrm{Q}$

The proposed binding mode of compound 10 revealed an affinity value of $-14.09 \mathrm{kcal} / \mathrm{mol}$. Residues SER 57 , TYR 58, CYS 170, TYR 186, ILE 196, GLN 204, VAL 292, CYS 395, GLY 432, TYR 433, MET 434 shows electrostatic interaction with compound 10 and hydrophobic cleft was formed by GLY 56, LEU 169, LYS 294, TYR 324 and PHE 341. 
Graphical representation of different parameters of lead compounds:

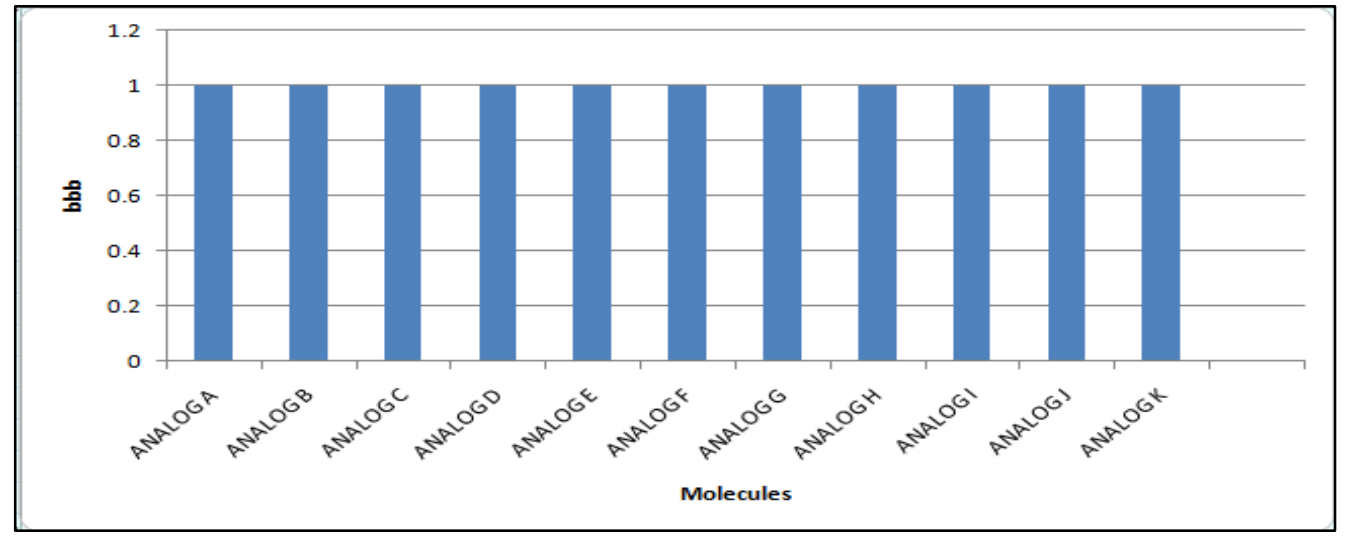

Figure 14: BBB values of lead compounds

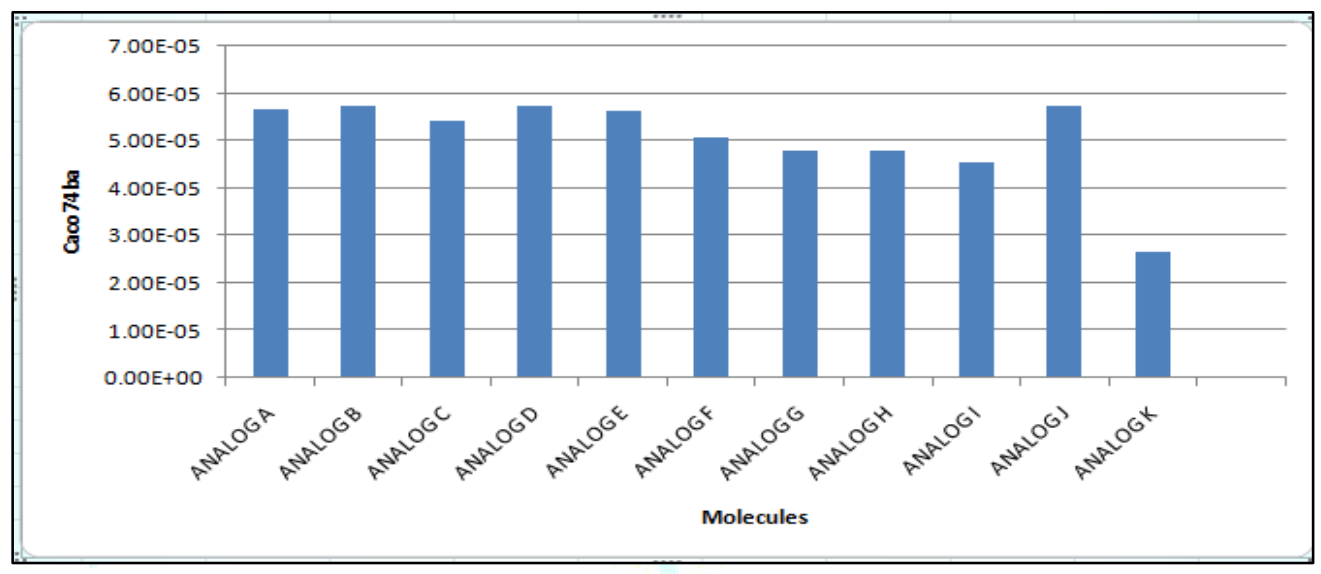

Figure 15: Caco 74ba values of lead compound

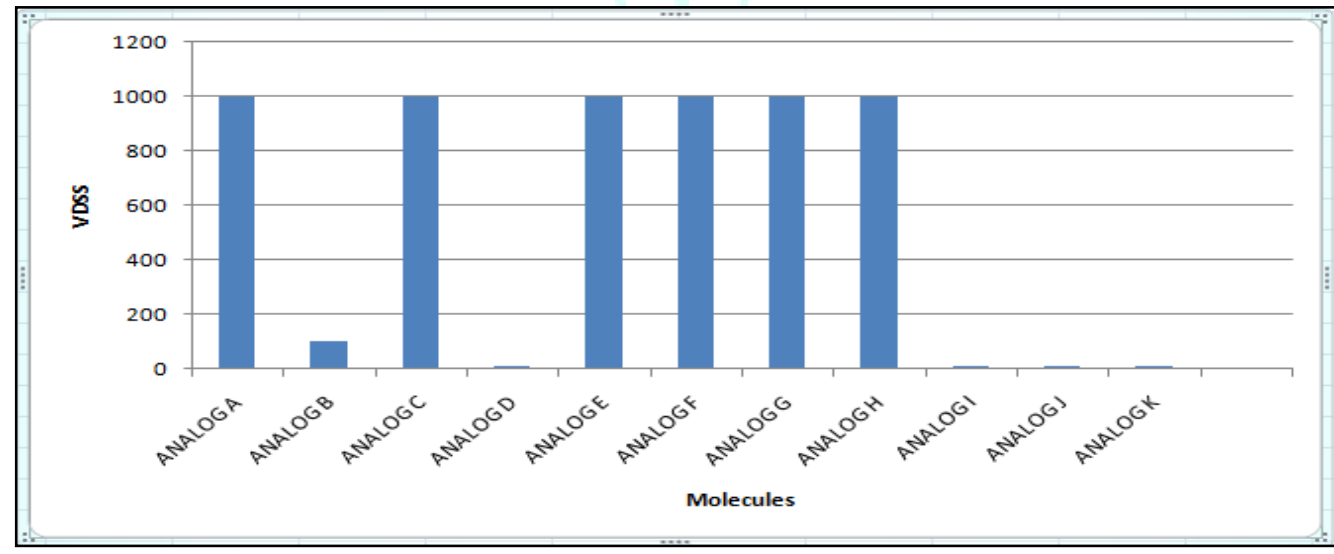

Figure 16: Vdss values of lead compounds

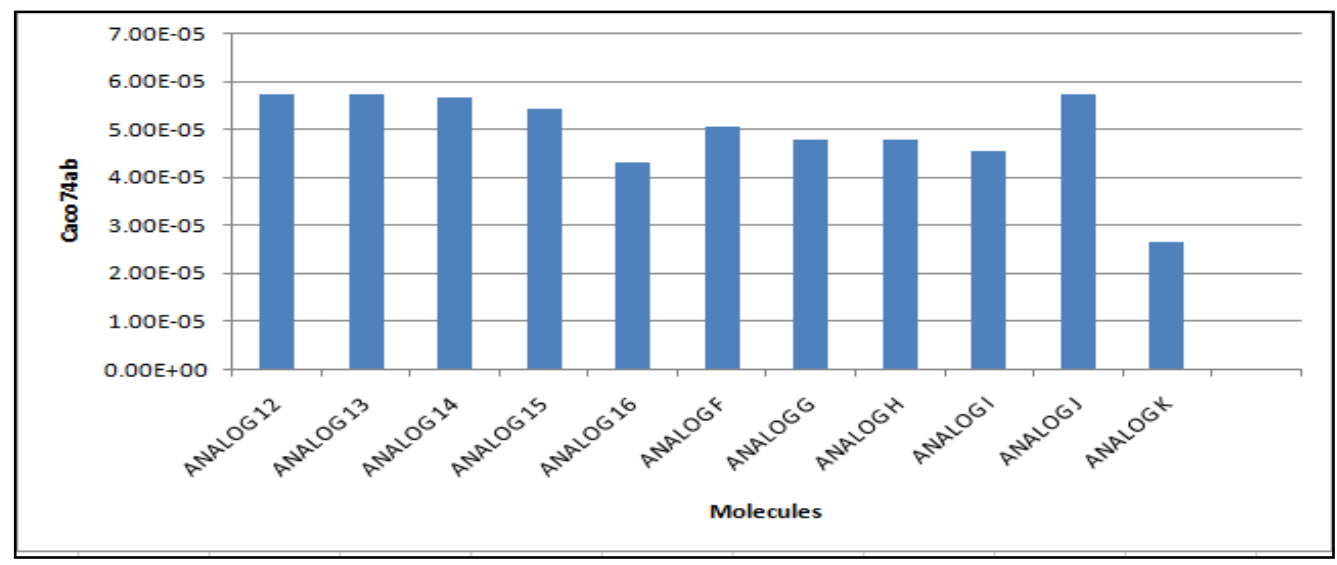

Figure 17: Caco74ab values of lead compounds 


\section{CONCLUSION}

Some novel derivatives were designed and molecular docking study was performed for prediction of MAO-B inhibitory activity. The binding mode of the proposed compounds with the target protein ie. 1S2Q was evaluated and the resulting data from the docking studies explained that all the newly designed derivatives had high and better affinity towards the target protein compared to rasagiline as a reference ligand. Among 15 derivatives, all the compounds have better bioaffinity values. Docking studies shows that the electrostatic and hydrophobic interactions with target molecule. It reveals that all the compounds occupy the same binding pocket in the active sites.

Compounds 4, 5, 6, 7, 10, 11, 14, 15 show the highest values of $\log \mathrm{p}$ as compared to the target protein. It is

\section{REFERENCES}

1. Rahman MM., Karim M.R., Ahsan MQ., Khalipha ABR., Chowdhury MR, \& Saifuzzaman M. Use of computer in drug design and drug discovery: A review. International Journal of Pharmaceutical and Life sciences, 2012; 1(2):1-21.

2. Ooms F. Molecular modeling and computer aided drug design. Examples of their applications in medical chemistry. Current medicinal chemistry, 2000; 7(2):141-158

3. Song, C. M., Lim, S. J., \& Tong, J. C. Recent advances in computer-aided drug design. Briefings in bioinformatics, 2009; 10(5):579-591.

4. Mechanism of neuroprotective action of the anti-parkinson drug rasagiline \& its derivatives. Mandel, S., Weinreb, O. Amit, T., Youdim, M. B. Brain Res. Brain Res. Rev.(2005)

5. Marrone TJ, Briggs, and JM, McCammon JA. Structure-based drug design: computational advances. Annual review of pharmacology and toxicology. 1997; 37(1):71-90.

6. Anderson AC. The process of structure-based drug design. Chemistry \& biology. 2003; 10(9):787-97. also predicted the structure based pharmacokinectic properties of all designed compounds by using pharmopredicta module of inventus v1.1 software and found that most of the final leads were similar as reference.

Compounds 2, 4, 9, 10, 11, 12, 13, 14, 15 shows the better values and conformation for BBB penetration.

The results shows that before synthesis, biological activity testing and clinical trials of new analogues, these drug designing methods are used for speeding up drug discovery process by eliminating less potent compounds from synthesis. It may have chances to show the better results than rasagiline in laboratory as well, therefore it could be used for future design, optimization and investigation to produce more effective analogues.

7. Schneider G, Böhm HJ. Virtual screening and fast automated docking methods. Drug discovery today. 2002; 7(1):64-70.

8. Waszkowycz B. Structure-based approaches to drug design and virtual screening. Current opinion in drug discovery \& development. 2002; 5(3):407-13.

9. Toledo-Sherman LM, Chen D. High-throughput virtual screening for drug discovery in parallel. Current opinion in drug discovery \& development. 2002; 5(3):414-21.

10. Muegge I, Rarey M. Small molecule docking and scoring. Reviews in computational chemistry. 2001; 17:1-60.

11. Verkhivker GM, Bouzida D, Gehlhaar DK, Rejto PA, Arthurs S, Colson AB, Freer ST, Larson V, Luty BA, Marrone T, Rose PW. Deciphering common failures in molecular docking of ligand-protein complexes. Journal of computer-aided molecular design. 2000; 14(8):731-51.

12. Stahl M, Rarey M. Detailed analysis of scoring functions for virtual screening. Journal of medicinal chemistry. 2001; 44(7):1035-42. 